\title{
Correlation between academic achievements and admission criteria at the School of Dentistry, Chonnam National University
}

\author{
Han-Joo Jung, Eun-Ju Lee*, and Min-Seok Kim
}

Dental Research Institute, School of Dentistry, Chonnam National University, Gwangju, Republic of Korea

This study analyzed the correlation between academic achievements and admission criteria at the School of Dentistry, Chonnam National University, to formulate suggestions to improve the admission criteria. The study population comprised 268 students admitted to the School of Dentistry between 2012 and 2015 who had completed at least one academic year. Academic achievements according to gender, age, former school, and recruitment differences (early/regular) were analyzed using a t-test. Dental Education Eligibility Test (DEET) score, Grade Point Average (GPA), Test of English Proficiency developed by Seoul National University (TEPS) score, and interviews were analyzed using Pearson's product moment correlation coefficients. The t-test results showed statistically significant differences in academic achievements according to gender and recruitment differences; girls and early admission-passed students performed better than boys and regularly-passed students. There was no statistically significant difference in academic achievements based on students' age and former school. GPA and DEET scores showed a significant correlation between academic achievements and admission criteria, while the TEPS and interview scores did not. There were also statistically significant differences in academic achievements based on gender and recruitment differences. These results can be used to better select outstanding students in the future.

Key Words: Academic success, Correlation of data, Graduate Dental Education, School admission criteria

(c) This is an open-access article distributed under the terms of the Creative Commons Attribution Non-Commercial License (http://creativecommons.org/licenses/by-nc/4.0) which permits unrestricted noncommercial use, distribution, and reproduction in any medium, provided the original work is properly cited.

\section{서 론}

2005년 전남대학교 치의학전문대학원은 치의예과 2년과 본 과 4 년을 이수하는 $2+4$ 과정의 치과대학에서 학부 4 년과 전문 대학원 4 년을 이수하는 $4+4$ 과정의 치의학전문대학원으로 학 제를 개편하고, 학사 학위 소지자들을 대상으로 70명의 신입생 을 선발하였다. 2014년 추가 개편을 통해 정원의 50\%인 35명 을 학사과정 3 년을 마친 후, 치의학전문대학원 석사과정 4 년을
이수하는 과정인 학·석사통합과정을 신설하였다. 따라서 학·석 사통합과정 학생들이 석사과정으로 진입한 2017년부터 나머지 $50 \%$ 인 35명의 학생들만을 석사과정 신입생으로 선발하였다. 전남대학교 치의학전문대학원 석사과정 신입생은 후에 국민건 강을 책임지는 의료인이 된다는 점뿐만 아니라, 의예과와 같은 예비 과정 없이 바로 전공 학습을 수행해야 하며, 이미 3년의 학 사과정을 마친 학·석사통합과정 학생들과 융화되어 학교생활을 해야 한다는 점에서 그 선발과정이 매우 중요하다. 또한 이전보

Received October 4, 2019; Revised November 21, 2019; Accepted November 21, 2019

*Co-corresponding author: Min-Seok Kim, Department of Oral Anatomy, School of Dentistry, Chonnam National University, 33 Yongbong-ro, Buk-gu, Gwangju 61186, Republic of Korea.

Tel: +82-62-530-4823, Fax: +82-62-530-4829, E-mail: greatone@jnu.ac.kr

${ }^{*}$ Co-corresponding author: Eun-Ju Lee, Department of Oral Anatomy, School of Dentistry, Chonnam National University, 33 Yongbong-ro, Buk-gu, Gwangju 61186, Republic of Korea.

Tel: +82-62-530-4821, Fax: +82-62-530-4829, E-mail: EunJu@jnu.ac.kr

Copyright () 2019, Oral Biology Research Institute 
다 선발하는 학생의 수가 줄어든 만큼, 학생을 선발하는 기준이 더욱 명확해질 필요성이 있다.

그 중요성에도 불구하고 전문대학원 신입생 선발에 관한 선 행연구는 드물다. 가천의과대학교와 충북대학교에서 의학전문 대학원의 입학전형요소와 학업성취도를 분석한 연구가 있으나, 이는 2005년, 2006년에 입학한 학생들을 대상으로 한 의학전문 대학원 도입 초기의 연구이며 치의학전문대학원을 대상으로 한 연구는 없다[1,2].

이에 본 연구에서는 전남대학교 치의학전문대학원 학생들의 학업성취도를 바탕으로, 입학 전형의 객관적인 지표들(성별, 연 령, 출신 학부대학, Dental Education Eligibility Test [DEET]점 수, Test of English Proficiency developed by Seoul National University [TEPS] 점수, 학부 Grade Point Average [GPA]점수, 면접점수, 모집구분 등)과의 상관관계를 분석하였다. 이를 통해 각각의 지표들이 입학 후의 학업성취도와 어떠한 관련이 있는 지를 확인한 후 신입생을 선발하는 과정에서 어떠한 지표들에 비중을 두어야 하는지 알아보았다.

\section{대상 및 방법}

본 연구는 2012년부터 2015년까지 전남대학교 치의학전문 대학원(1년 정원 70명)에 입학한 인원 중 최소 1년 이상의 교육 을 이수한 268명(2012년: 66명; 2013년: 66명; 2014년: 66명; 2015년: 70명)을 대상으로 했다.

학업성취도에 영향을 줄 수 있는 개개인의 특성을 성별, 연 령, 출신학교로 나누어 학업성취도와 비교했고, 입학전형요소인 DEET점수, TEPS점수, 학부 GPA점수, 면접점수 그리고 모집구 분(수시/정시)에 따라 각각 학업성취도와 비교했다. 학업성취도 는 전체평균점수, 기초치의학 과목점수, 임상치의학 과목점수 로 나누어 각각의 요소들과 비교했다. 단, 임상치의학 과목점수 의 경우에는 2015 년 입학생 70 명과 휴학이나 유급 등의 이유로
8 명이 이수하지 못했다. 임상치의학 과목점수는 268 명 중 190 명(2012년: 66명; 2013년: 63명; 2014년: 61명)만을 대상으로 분석했다.

성별, 연령, 출신학교, 모집구분에 따른 학업성취도의 분석은 학생들을 기준에 따라 독립된 두 그룹으로 나눈 후 각 그룹의 학 업성취도를 서로 비교했다. t-test 혹은 t-검정을 통해 서로 독립 적인 두 집단의 모평균을 비교할 수 있으므로 t-test를 통해 통 계분석을 실시했다[3]. 반면 DEET, GPA, TEPS, 면접점수와 학 업성취도를 비교하는 경우, 두 연속변수가 서로 어떤 관계를 가 지는지 확인할 수 있는 상관계수(r)를 구해 분석했다[4]. 이는 선 행연구인 가천의과대학교나 충북대학교에서의 연구방법과 유 사한 것이다(Table 1) [1,2].

성별에 따른 학업성취도의 차이를 확인하기 위해 t-test를 사 용했다. 연령은 입학 당시의 평균연령을 기준으로 두 그룹으로 나눈 뒤 두 그룹의 학업성취도를 t-test를 통해 분석했다. 출신 학교는 두 가지 기준에 따라 두 그룹으로 나눈 뒤 t-test를 통해 각각의 그룹 간에 차이가 있는지 비교했다. 첫 번째로 지역에 따 라 서울과 지방 소재 대학으로 나누었고, 두 번째로는 서울대학 교, 고려대학교, 연세대학교, 한국과학기술원, 포항공과대학교 와 그 외 다른 학교들로 구분해서 비교했다. 또한, 학생들을 모 집구분에 따라 수시/정시 합격자로 구분하여 두 그룹을 t-test를 통해 비교했다.

입학전형요소를 비교하기 위해 DEET점수(자연과학추론1 [생 물], 자연과학추론2 [화학, 유기화학, 물리]로 구분, 2012년 입 학생의 경우 언어추론과목도 존재했으나, 앞으로 입학할 학생 들에게는 해당되지 않아 분석할 항목으로 포함시키지 않음), TEPS점수, 학부 GPA, 면접점수를 Pearson의 상관계수를 이용 하여 학업성취도와 비교했다.

MS Excel 2013 (Microsoft, Redmond, WA, USA)과 IBM SPSS Statistics ver. 25.0 (IBM Corp., Armonk, NY, USA)를 이 용해 자료를 통계 분석했고, 자료의 시각화를 위해 Adobe Il-

Table 1. Method of statistical analysis on each study

\begin{tabular}{|c|c|c|c|c|c|c|c|c|}
\hline & Gender & Age & $\begin{array}{l}\text { Former } \\
\text { school }\end{array}$ & Recruitment & $\begin{array}{c}\text { DEET } \\
(\text { MEET) }\end{array}$ & GPA & $\begin{array}{c}\text { TEPS } \\
\text { (English test) }\end{array}$ & Interview \\
\hline $\begin{array}{l}\text { School of Dentistry, } \\
\text { Chonnam National University }\end{array}$ & t-test & t-test & t-test & t-test & $\mathrm{r}$ & $\mathrm{r}$ & $\mathrm{r}$ & $\mathrm{r}$ \\
\hline $\begin{array}{l}\text { Gachon University College of } \\
\text { Medicine }\end{array}$ & t-test & t-test & - & - & $\mathrm{r}$ & $\mathrm{r}$ & $\mathrm{r}$ & $\mathrm{r}$ \\
\hline $\begin{array}{l}\text { Chungbuk National University } \\
\text { of Medicine }\end{array}$ & t-test & t-test & - & - & $\mathrm{r}$ & $\mathrm{r}$ & $\mathrm{r}$ & - \\
\hline
\end{tabular}

DEET, Dental Education Eligibility Test; MEET, Medical Education Eligibility Test; GPA, Grade Point Average; TEPS, Test of English Proficiency developed by Seoul National University, r, correlation coefficient; -, not available.

${ }^{a}$ This study. 
lustrator 프로그램을 사용했다.

\section{결 과}

\section{성별에 따른 학업성취도}

각 연도별 신입생의 성비를 Table 2에 정리했고, 이를 바탕으 로 분석한 성별에 따른 학업성취도를 Table 3과 Fig. 1에 나타냈 다. 2015년 입학생을 제외하고 성별학업성취도는 여성에서 뚜 렷하게 높았고, 기초치의학 과목성적보다 임상치의학 과목성적 에서 그 차이가 더 큰 양상을 보였다.

Table 2. Number of students by gender

\begin{tabular}{cccc}
\hline $\begin{array}{c}\text { Year of } \\
\text { admission }\end{array}$ & Total & Gender & Number of students \\
\hline 2012 & 66 & M & $32(48.5)$ \\
& & W & $34(51.5)$ \\
2013 & 66 & M & $44(66.7)$ \\
& & W & $22(33.3)$ \\
2014 & 66 & M & $40(60.6)$ \\
& & W & $26(39.4)$ \\
Total & 70 & M & $38(54.3)$ \\
& 268 & W & $32(45.7)$ \\
& & M & $154(57.5)$ \\
& & W & $114(42.5)$ \\
\hline
\end{tabular}

Values are presented as number only or number (\%).

$\mathrm{M}$, men; W, women.

\section{연령에 따른 학업성취도}

학년별 평균 입학연령은 26.4-27.3세이며, 전체평균 입학연 령은 27.0세였다. 이에 27세를 기준으로, 27 세 이상인 그룹과 27세 미만인 그룹으로 나누어 학업성취도를 비교했다(Table 4). 연령에 따른 학년별 학업성취도는 전반적으로 연령이 어린 그 룹에서 높은 것으로 보였으나, 그 차이가 통계적으로 유의하지 않았다. 그러나 전체 학생을 대상으로 전체점수를 비교했을 때 두 그룹 사이에 유의한 차이가 있음을 확인할 수 있었다(Table 5, Fig. 2).

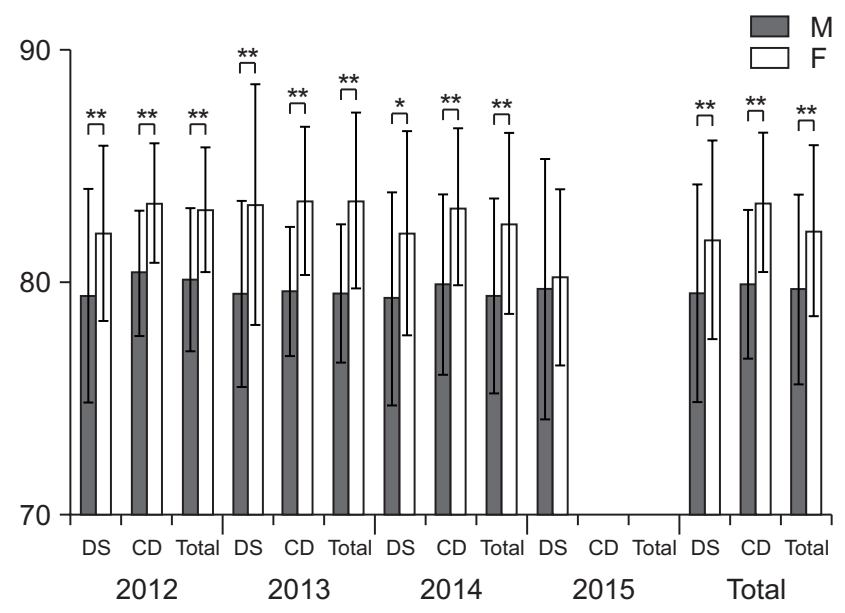

Fig. 1. Graph of analysis results between academic achievements and gender. DS: dental science, CD: clinical dentistry. ${ }^{\star} p<0.05,{ }^{\star *} p<0.01$.

Table 3. Analysis results between academic achievements and gender

\begin{tabular}{|c|c|c|c|c|c|c|c|c|c|c|}
\hline \multirow{2}{*}{$\begin{array}{c}\text { Year of } \\
\text { admission }\end{array}$} & \multirow{2}{*}{ Gender } & \multicolumn{3}{|c|}{ Dental science } & \multicolumn{3}{|c|}{ Clinical dentistry } & \multicolumn{3}{|c|}{ Total average } \\
\hline & & Mean & SD & $\mathbf{t}$ & Mean & SD & $\mathbf{t}$ & Mean & SD & t \\
\hline \multirow[t]{2}{*}{2012} & M & 79.4 & 4.6 & $-2.7^{\star \star}$ & 80.4 & 2.7 & $-4.7^{\star \star}$ & 80.1 & 3.1 & $-4.2^{\star *}$ \\
\hline & W & 82.1 & 3.8 & & 83.4 & 2.6 & & 83.1 & 2.7 & \\
\hline \multirow[t]{2}{*}{2013} & M & 79.5 & 4.0 & $-3.3^{* *}$ & 79.6 & 2.8 & $-5.0^{* *}$ & 79.5 & 3.0 & $-4.6^{* *}$ \\
\hline & $\mathrm{W}$ & 83.3 & 5.2 & & 83.5 & 3.2 & & 83.5 & 3.8 & \\
\hline \multirow[t]{2}{*}{2014} & M & 79.3 & 4.6 & $-2.6^{*}$ & 79.9 & 3.9 & $-3.4^{\star *}$ & 79.4 & 4.2 & $-3.0^{\star *}$ \\
\hline & $\mathrm{W}$ & 82.1 & 4.4 & & 83.2 & 3.4 & & 82.5 & 3.9 & \\
\hline \multirow[t]{2}{*}{2015} & M & 79.7 & 5.6 & -0.5 & & - & & & - & \\
\hline & $\mathrm{W}$ & 80.2 & 3.8 & & & & & & & \\
\hline \multirow[t]{2}{*}{ Total } & M & 79.5 & 4.7 & $-4.2^{\star *}$ & 79.9 & 3.2 & $-7.6^{* *}$ & 79.7 & 4.1 & $-5.3^{\star *}$ \\
\hline & $\mathrm{W}$ & 81.8 & 4.3 & & 83.4 & 3.0 & & 82.2 & 3.7 & \\
\hline
\end{tabular}

M, men; W, women; SD, standard deviation; -, not available.

${ }^{\star} p<0.05,{ }^{* *} p<0.01$. 


\section{출신학교에 따른 학업성취도}

대상 학생들의 출신학교를 두 가지 기준으로 분류했다. 먼저 출신 학교의 소재지에 따라 서울 소재 대학(제1군)과 지방 소재 대학(제2군)으로 나누었고, 두 번째로 서울대학교, 고려대학교, 연세대학교, 한국과학기술원, 포항공과대학교(제3군)와 그 외 대학(제4군)으로 나누었다(Table 6). 출신 학교의 소재지에 따라 나눈 두 군 간의 기초치의학 점수와 전체평균 점수에서 유의한 차이가 나타났지만, 두 번째 기준에 따른 분류 두 군 간의 유의 한 차이는 없었다(Table 7, Fig. 3).

\section{모집구분(수시/정시)에 따른 학업성취도}

각 입학 연도에 따라 수시/정시 합격생의 비율을 Table 8에 정리했다. 전반적으로 수시모집을 통해 입학한 학생들이 정시

Table 4. Number of students by age

\begin{tabular}{ccccc}
\hline $\begin{array}{c}\text { Year of } \\
\text { admission }\end{array}$ & Total & Average & Classification & $\begin{array}{c}\text { Number of } \\
\text { students }\end{array}$ \\
\hline 2012 & 66 & 26.4 & $\geq 27$ & $26(39.4)$ \\
& & & $<27$ & $40(60.6)$ \\
2013 & 66 & 27.0 & $\geq 27$ & $28(42.4)$ \\
& & & $<27$ & $38(57.6)$ \\
2014 & 66 & 27.2 & $\geq 27$ & $32(48.5)$ \\
& & & $<27$ & $34(51.5)$ \\
2015 & 70 & 27.3 & $\geq 27$ & $37(52.9)$ \\
& & & $<27$ & $33(47.1)$ \\
Total & 268 & 27.0 & $\geq 27$ & $123(45.9)$ \\
& & & $<27$ & $145(54.1)$ \\
\hline
\end{tabular}

Values are presented as number only or number (\%).
모집을 통해 입학한 학생보다 학업성취도가 높았다. 이런 양상 은 기초치의학 과목점수보다 임상치의학 과목점수에서 두드 러졌으나, 2015년 입학생에서는 거의 차이가 없었다(Table 9, Fig. 4).

\section{치의학 입문검사(Dental Education Eligibility Test) 점수 와 학업성취도 상관관계}

DEET점수는 자연추론 1 , 자연추론 2 , 전체 DEET점수로 구 분하여 각각을 학업성취도와 비교했다(Table 10-12). 전반적 으로 DEET점수와 학업성취도 사이에는 유의한 상관관계가 없 었으나, 전체학생을 대상으로 했을 때 기초치의학 과목점수와 전체 DEET점수 사이에서 유의한 상관관계를 보였다 $(\mathrm{r}=0.146-$

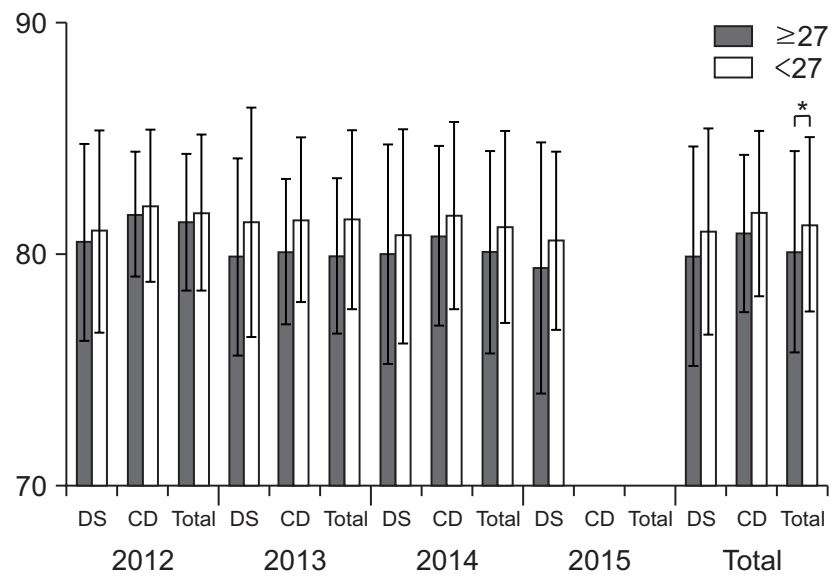

Fig. 2. Graph of analysis results between academic achievements and age. DS, dental science; $C D$, clinical dentistry. ${ }^{*} p<0.05$.

Table 5. Analysis results between academic achievements and age

\begin{tabular}{|c|c|c|c|c|c|c|c|c|c|c|}
\hline \multirow{2}{*}{$\begin{array}{c}\text { Year of } \\
\text { admission }\end{array}$} & \multirow{2}{*}{ Age } & \multicolumn{3}{|c|}{ Dental science } & \multicolumn{3}{|c|}{ Clinical dentistry } & \multicolumn{3}{|c|}{ Total average } \\
\hline & & Mean & SD & $\mathbf{t}$ & Mean & SD & $\mathbf{t}$ & Mean & SD & $\mathbf{t}$ \\
\hline \multirow[t]{2}{*}{2012} & $\geq 27$ & 80.5 & 4.3 & -0.4 & 81.7 & 2.7 & -0.5 & 81.4 & 3.0 & -0.5 \\
\hline & $<27$ & 81.0 & 4.4 & & 82.1 & 3.3 & & 81.8 & 3.4 & \\
\hline \multirow[t]{2}{*}{2013} & $\geq 27$ & 79.9 & 4.3 & -1.3 & 80.1 & 3.2 & -1.5 & 79.9 & 3.4 & -1.7 \\
\hline & $<27$ & 81.4 & 5.0 & & 81.5 & 3.6 & & 81.5 & 3.9 & \\
\hline \multirow[t]{2}{*}{2014} & $\geq 27$ & 80.0 & 4.8 & -0.7 & 80.8 & 3.9 & -0.8 & 80.1 & 4.4 & -1.0 \\
\hline & $<27$ & 80.8 & 4.7 & & 81.7 & 4.1 & & 81.2 & 4.2 & \\
\hline \multirow[t]{2}{*}{2015} & $\geq 27$ & 79.4 & 5.5 & -1.0 & & - & & & - & \\
\hline & $<27$ & 80.6 & 3.9 & & & & & & & \\
\hline \multirow[t]{2}{*}{ Total } & $\geq 27$ & 79.9 & 4.8 & -1.9 & 80.9 & 3.4 & -1.7 & 80.1 & 4.4 & $-2.4^{*}$ \\
\hline & $<27$ & 81.0 & 4.5 & & 81.8 & 3.6 & & 81.3 & 3.8 & \\
\hline
\end{tabular}

SD, standard deviation; -, not available. ${ }^{*} p<0.05$. 
0.247). 2015년 입학생의 경우 자연추론 1 점수와 기초치의학 과목점수 간의 상관관계가 매우 컸다(r=0.417).

Table 6. Classification by former school

\begin{tabular}{ccc}
\hline Classification & No. of students & Total \\
\hline Group 1 & $112(41.8)$ & 268 \\
Group 2 & $156(58.2)$ & \\
Group 3 & $76(28.4)$ & \\
Group 4 & $192(71.6)$ & \\
\hline
\end{tabular}

Values are presented as number (\%) or number only.

Group 1: universities in Seoul, group 2: university in a province, group 3: Seoul National University, Korea University, Yonsei University, Korea Advanced Institute of Science and Technology, Pohang University of Science and Technology, group 4: other universities.

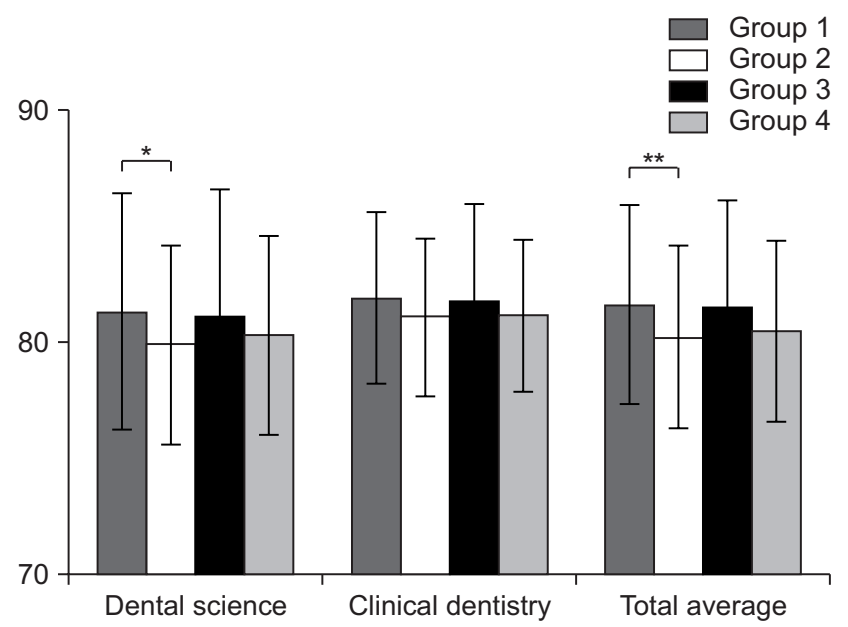

Fig. 3. Graph of analysis results between academic achievements and former school. Group 1: universities in Seoul, group 2: university in a province, group 3: Seoul National University, Korea University, Yonsei University, Korea Advanced Institute of Science and Technology, Pohang University of Science and Technology, group 4: other universities. ${ }^{*} p<0.05,{ }^{* *} p<0.01$.
영어능력검증시험(Test of English Proficiency developed by Seoul National University) 점수와 학업 성취도 상관관계

TEPS점수와 학업성취도 간에는 큰 상관관계가 있다고 보 기 어려웠다. 단, 2012학년도 입학생의 임상치의학 과목점수 $(\mathrm{r}=0.246)$, 전체 학생의 임상치의학 과목 점수와 전체 평균점수 $(\mathrm{r}=0.129-0.169)$ 는 TEPS점수와 통계적으로 유의한 상관성을 보였으나 상관계수는 크지 않았다(Table 13).

\section{평점 평균 (Grade Point Average) 점수와 학업성취도 상관 관계}

학부 GPA점수와 학업성취도 간에는 대부분 통계적으로 유의 한 상관관계가 있었으며, 특히 2012년 입학생들에서 상관계수 가 매우 컸다(r=0.506-0.536). 그리고 전반적으로 기초치의학 과목점수보다는 임상치의학 과목점수와 더 깊은 상관관계가 있 었다(Table 14).

Table 8. Number of students by recruitment method

\begin{tabular}{cclc}
\hline $\begin{array}{c}\text { Year of } \\
\text { admission }\end{array}$ & Total & Method & No. of students \\
\hline 2012 & 66 & Early & $17(25.8)$ \\
2013 & & Regular & $49(74.2)$ \\
& 66 & Early & $16(24.2)$ \\
2014 & \multirow{2}{*}{66} & Regular & $50(75.8)$ \\
& & Early & $15(22.7)$ \\
2015 & \multirow{2}{*}{70} & Regular & $51(77.3)$ \\
& & Early & $22(31.4)$ \\
Total & 268 & Regular & $48(68.6)$ \\
& & Early & $70(26.1)$ \\
& & Regular & $198(73.9)$ \\
\hline
\end{tabular}

Values are presented as number only or number (\%).

Table 7. Analysis results between academic achievements and former school

\begin{tabular}{|c|c|c|c|c|c|c|c|c|c|}
\hline \multirow{2}{*}{ Classification } & \multicolumn{3}{|c|}{ Dental science } & \multicolumn{3}{|c|}{ Clinical dentistry } & \multicolumn{3}{|c|}{ Total average } \\
\hline & Mean & SD & $\mathbf{t}$ & Mean & SD & $\mathbf{t}$ & Mean & SD & t \\
\hline Group 1 & 81.3 & 5.1 & $2.4^{*}$ & 81.9 & 3.7 & 1.6 & 81.6 & 4.3 & $2.7^{\star *}$ \\
\hline Group 2 & 79.9 & 4.3 & & 81.1 & 3.4 & & 80.2 & 3.9 & \\
\hline Group 3 & 81.1 & 5.5 & 1.2 & 81.8 & 4.2 & 0.9 & 81.5 & 4.6 & 1.9 \\
\hline Group 4 & 80.3 & 4.3 & & 81.2 & 3.2 & & 80.5 & 3.9 & \\
\hline
\end{tabular}

Group 1: universities in Seoul, group 2: university in a province, group 3: Seoul National University, Korea University, Yonsei University, Korea Advanced Institute of Science and Technology, Pohang University of Science and Technology, group 4: other universities.

$\mathrm{SD}$, standard deviation.

${ }^{\star} p<0.05,{ }^{* *} p<0.01$. 
Table 9. Analysis results between academic achievements and recruitment difference

\begin{tabular}{|c|c|c|c|c|c|c|c|c|c|c|}
\hline \multirow{2}{*}{$\begin{array}{c}\text { Year of } \\
\text { admission }\end{array}$} & \multirow{2}{*}{ Method } & \multicolumn{3}{|c|}{ Dental science } & \multicolumn{3}{|c|}{ Clinical dentistry } & \multicolumn{3}{|c|}{ Total average } \\
\hline & & Mean & SD & $\mathbf{t}$ & Mean & SD & $\mathbf{t}$ & Mean & SD & $\mathbf{t}$ \\
\hline \multirow[t]{2}{*}{2012} & Early & 82.0 & 3.7 & 1.4 & 83.6 & 2.8 & $2.8^{* *}$ & 83.2 & 2.8 & $2.4^{*}$ \\
\hline & Regular & 80.4 & 4.5 & & 81.4 & 2.9 & & 81.1 & 3.2 & \\
\hline \multirow[t]{2}{*}{2013} & Early & 82.8 & 4.9 & 2.0 & 82.5 & 2.7 & 2.0 & 82.3 & 3.6 & 1.8 \\
\hline & Regular & 80.1 & 4.6 & & 80.5 & 3.6 & & 80.4 & 3.7 & \\
\hline \multirow[t]{2}{*}{2014} & Early & 83.7 & 4.1 & $3.3^{* *}$ & 84.5 & 3.0 & $3.6^{* *}$ & 83.7 & 3.8 & $3.3^{* *}$ \\
\hline & Regular & 79.4 & 4.5 & & 80.4 & 3.8 & & 79.8 & 4.1 & \\
\hline \multirow[t]{2}{*}{2015} & Early & 80.5 & 4.8 & 0.6 & & - & & & - & \\
\hline & Regular & 79.7 & 4.9 & & & & & & & \\
\hline \multirow[t]{2}{*}{ Total } & Early & 82.1 & 4.5 & $3.4^{\star *}$ & 83.5 & 2.9 & $4.8^{* *}$ & 82.2 & 4.0 & $3.6^{* *}$ \\
\hline & Regular & 79.9 & 4.6 & & 80.8 & 3.5 & & 80.2 & 4.0 & \\
\hline
\end{tabular}

SD, standard deviation, -, not available. ${ }^{\star} p<0.05,{ }^{* *} p<0.01$.

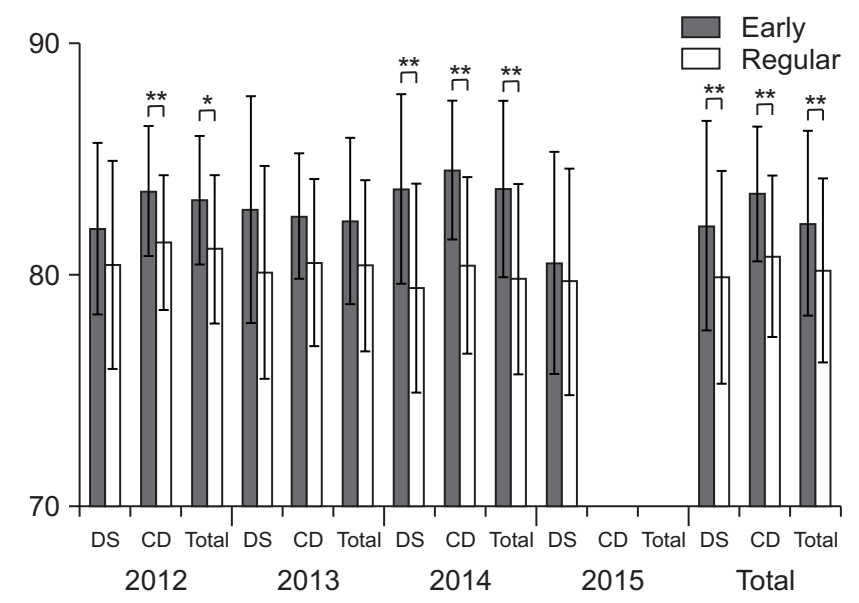

Fig. 4. Graph of analysis results between academic achievements and recruitment difference. DS, dental science; CD, clinical dentistry. ${ }^{\star} p<0.05,{ }^{* *} p<0.01$.

\section{면접점수와 학업성취도 상관관계}

전체학생을 대상으로 면접점수를 임상치의학 과목점수, 혹은 전체 평균점수와 비교했을 때 통계적으로 유의한 상관성을 보 였으나 상관도는 낮았다 $(\mathrm{r}=0.138-0.145)$. 그 외 면접점수와 다 른 항목의 학업성취도 사이 상관성은 없었다(Table 15).

\section{결과요약}

이상의 결과들을 종합하여 Fig. 5와 Fig. 6에 나타냈다. t-test 를 통해 분석한 Fig. 5의 y축은 $\mathrm{t}$ 통계량의 절대 값으로, 이 값이 클수록 두 그룹의 차이가 명확하다는 뜻이다. 따라서 성별에 따
Table 10. Analysis results between academic achievements and subject 1 score in DEET

\begin{tabular}{cccc}
\hline $\begin{array}{c}\text { Year of } \\
\text { admission }\end{array}$ & $\begin{array}{c}\text { Dental } \\
\text { science }\end{array}$ & $\begin{array}{c}\text { Clinical } \\
\text { dentistry }\end{array}$ & $\begin{array}{c}\text { Total } \\
\text { average }\end{array}$ \\
\hline 2012 & & & \\
r & 0.058 & -0.038 & -0.012 \\
$p$-value & 0.643 & 0.762 & 0.924 \\
2013 & & & \\
r & 0.136 & 0.106 & 0.136 \\
$p$-value & 0.276 & 0.407 & 0.276 \\
2014 & & & \\
r & 0.226 & 0.151 & 0.163 \\
$p$-value & 0.068 & 0.246 & 0.192 \\
2015 & & - & - \\
r & $0.417^{*}$ & & \\
$p$-value & $0.000^{*}$ & & \\
Total & & & $0.184^{*}$ \\
r & $0.209^{*}$ & 0.057 & $0.003^{*}$ \\
$p$-value & $0.001^{*}$ & 0.431 &
\end{tabular}

DEET, Dental Education Eligibility Test; -, not available.

${ }^{\star}$ Statistically significant.

른 학업성취도의 차이가 가장 명확하며, 다음으로 모집구분에 따른 학업성취도의 차이가 뚜렷하게 나타났다. 반면, 연령이나 출신대학에 따라서는 몇 개 항목에서 유의한 차이를 나타내기 는 하지만, 그 수준이 매우 미약했다. 상관계수분석을 통한 결과 들을 정리한 Fig. 6의 y축은 상관계수(r)이다. 이 값이 클수록 입 학전형요소와 학업성취도가 밀접한 연관을 가진다는 것을 의미 한다. GPA, DEET 순으로 학업성취도와의 상관관계가 뚜렷했 다. TEPS와 면접점수는 일부에서 통계적으로 유의한 상관성을 보였으나, 그 정도가 크지 않았다. 
Table 11. Analysis results between academic achievements and subject 2 score in DEET

\begin{tabular}{cccc}
\hline $\begin{array}{c}\text { Year of } \\
\text { admission }\end{array}$ & $\begin{array}{c}\text { Dental } \\
\text { science }\end{array}$ & $\begin{array}{c}\text { Clinical } \\
\text { dentistry }\end{array}$ & $\begin{array}{c}\text { Total } \\
\text { average }\end{array}$ \\
\hline 2012 & & & \\
r & 0.240 & 0.236 & 0.242 \\
$p$-value & 0.053 & 0.057 & 0.051 \\
2013 & & & \\
r & 0.169 & 0.095 & 0.138 \\
$p$-value & 0.174 & 0.458 & 0.269 \\
2014 & & & \\
r & 0.079 & -0.086 & 0.013 \\
$p$-value & 0.527 & 0.512 & 0.915 \\
2015 & & - & - \\
r & 0.151 & & \\
$p$-value & 0.211 & & \\
Total & & 0.072 & $0.017^{*}$ \\
r & $0.163^{*}$ & 0.321 & \\
$p$-value & $0.007^{*}$ &
\end{tabular}

DEET, Dental Education Eligibility Test; -, not available. ${ }^{\star}$ Statistically significant.

Table 12. Analysis results between academic achievements and DEET score

\begin{tabular}{cccc}
\hline $\begin{array}{c}\text { Year of } \\
\text { admission }\end{array}$ & $\begin{array}{c}\text { Dental } \\
\text { science }\end{array}$ & $\begin{array}{c}\text { Clinical } \\
\text { dentistry }\end{array}$ & $\begin{array}{c}\text { Total } \\
\text { average }\end{array}$ \\
\hline 2012 & & & \\
r & 0.218 & 0.147 & 0.169 \\
$p$-value & 0.078 & 0.240 & 0.174 \\
2013 & & & \\
r & 0.207 & 0.138 & 0.187 \\
$p$-value & 0.096 & 0.280 & 0.134 \\
2014 & & & \\
r & 0.206 & 0.040 & 0.118 \\
$p$-value & 0.096 & 0.762 & 0.345 \\
2015 & & - & - \\
r & $0.323^{*}$ & & \\
$p$-value & $0.006^{*}$ & & \\
Total & & & $0.219^{*}$ \\
r & $0.247^{*}$ & 0.091 & $0.000^{*}$ \\
$p$-value & $0.000^{*}$ & 0.211 & \\
\hline
\end{tabular}

DEET, Dental Education Eligibility Test; -, not available.

*Statistically significant.

\section{고 찰}

본 연구에서는 2012년부터 2015년까지 전남대학교 치의학 전문대학원 석사과정에 입학한 학생들의 학업성취도를 기초치 의학 과목성적, 임상치의학 과목성적, 전체성적으로 나누어 여 러 입학전형요소들과 비교했다. 그 결과, 성별에 따른 차이는 있
Table 13. Analysis results between academic achievements and TEPS score

\begin{tabular}{cccc}
\hline $\begin{array}{c}\text { Year of } \\
\text { admission }\end{array}$ & $\begin{array}{c}\text { Dental } \\
\text { science }\end{array}$ & $\begin{array}{c}\text { Clinical } \\
\text { dentistry }\end{array}$ & $\begin{array}{c}\text { Total } \\
\text { average }\end{array}$ \\
\hline 2012 & & & \\
r & 0.165 & $0.246^{*}$ & 0.230 \\
$p$-value & 0.186 & $0.047^{*}$ & 0.063 \\
2013 & & & \\
r & 0.124 & 0.057 & 0.096 \\
$p$-value & 0.322 & 0.657 & 0.443 \\
2014 & & & \\
r & 0.084 & 0.173 & 0.074 \\
$p$-value & 0.503 & 0.183 & 0.555 \\
2015 & & - & - \\
r & 0.071 & & \\
$p$-value & 0.560 & & \\
Total & & & $0.129^{*}$ \\
r & 0.116 & $0.169^{*}$ & $0.035^{*}$ \\
$p$-value & 0.057 & $0.020^{*}$ & \\
\hline
\end{tabular}

TEPS, Test of English Proficiency developed by Seoul National University; -, not available.

${ }^{\star}$ Statistically significant.

Table 14. Analysis results between academic achievements and GPA

\begin{tabular}{cccc}
\hline $\begin{array}{c}\text { Year of } \\
\text { Admission }\end{array}$ & $\begin{array}{c}\text { Dental } \\
\text { Science }\end{array}$ & $\begin{array}{c}\text { Clinical } \\
\text { Dentistry }\end{array}$ & $\begin{array}{c}\text { Total } \\
\text { average }\end{array}$ \\
\hline 2012 & & & \\
r & $0.512^{*}$ & $0.506^{*}$ & $0.536^{*}$ \\
$p$-value & $0.000^{*}$ & $0.000^{*}$ & $0.000^{*}$ \\
2013 & & & \\
r & 0.214 & $0.250^{*}$ & 0.229 \\
$p$-value & 0.084 & $0.048^{*}$ & 0.064 \\
2014 & & & \\
r & $0.345^{*}$ & $0.398^{*}$ & $0.385^{*}$ \\
$p$-value & $0.005^{*}$ & $0.001^{*}$ & $0.001^{*}$ \\
2015 & & - & - \\
r & 0.201 & & \\
$p$-value & 0.095 & & $0.322^{*}$ \\
Total & & & $0.000^{*}$ \\
r & $0.316^{*}$ & $0.383^{*}$ & \\
$p$-value & $0.000^{*}$ & $0.000^{*}$ &
\end{tabular}

GPA, Grade Point Average; -, not available.

${ }^{\star}$ Statistically significant.

었으나 연령이나 출신학교에 따른 차이는 발견하기 어려웠다. $\mathrm{GPA}$ 와 DEET성적은 학업성취도와 유의한 상관관계가 있었으 나, TEPS나 면접점수는 상관관계가 없었다. 또한, 수시로 합격 한 학생들이 정시로 합격한 학생들보다 우수한 학업성취도를 보였다.

여러 요소들 중 첫 번째로 성별에 따라 학업성취도의 차이가 
Table 15. Analysis results between academic achievements and interview score

\begin{tabular}{cccc}
\hline $\begin{array}{c}\text { Year of } \\
\text { admission }\end{array}$ & $\begin{array}{c}\text { Dental } \\
\text { science }\end{array}$ & $\begin{array}{c}\text { Clinical } \\
\text { dentistry }\end{array}$ & $\begin{array}{c}\text { Total } \\
\text { average }\end{array}$ \\
\hline 2012 & & & \\
r & -0.006 & 0.128 & 0.093 \\
$p$-value & 0.959 & 0.306 & 0.456 \\
2013 & & & \\
r & 0.214 & 0.054 & 0.180 \\
$p$-value & 0.084 & 0.676 & 0.149 \\
2014 & & & \\
r & 0.180 & 0.193 & 0.165 \\
$p$-value & 0.148 & 0.137 & 0.185 \\
2015 & & - & - \\
r & 0.031 & & \\
$p$-value & 0.802 & & \\
Total & & & $0.138^{*}$ \\
r & 0.119 & $0.145^{*}$ & $0.024^{*}$ \\
$p$-value & 0.052 & $0.045^{*}$ &
\end{tabular}

-, not available.

*Statistically significant.

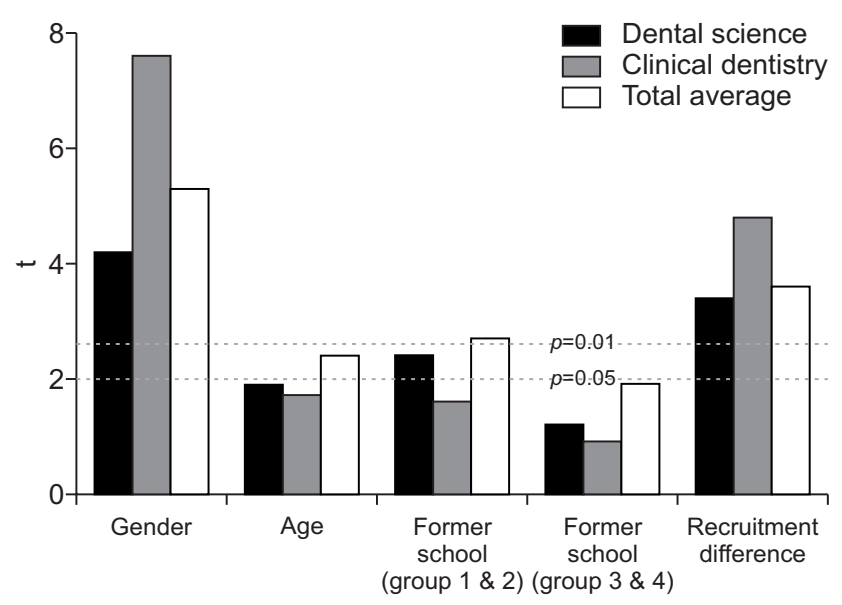

Fig. 5. Comparison of analysis results by t-test. Group 1: universities in Seoul, group 2: university in a province, group 3: Seoul National University, Korea University, Yonsei University, Korea Advanced Institute of Science and Technology, Pohang University of Science and Technology, group 4: other universities.

있음을 확인했다. 이는 고려대학교나 연세대학교의 보고와 동 일하며, 울산대학교 의예과 학생들을 대상으로 한 연구결과 일 부와도 동일한 결과였다[5-7]. 그러나 과천의과학대학교나 충 북대학교 의학전문대학원에서는 성별과 학업성취도 간에 상관 관계가 없었고, Peng 등[8]도 임상전 과정의 학업성취도가 성별 과 무관하다고 보고하였다[1,2]. 한편, 저학년에서는 오히려 남 학생의 성적이 우수하다가 학년이 올라갈수록 여학생들의 성적 이 더 우수해졌다는 Ramsbottom-Lucier 등[9]의 보고는, 기초

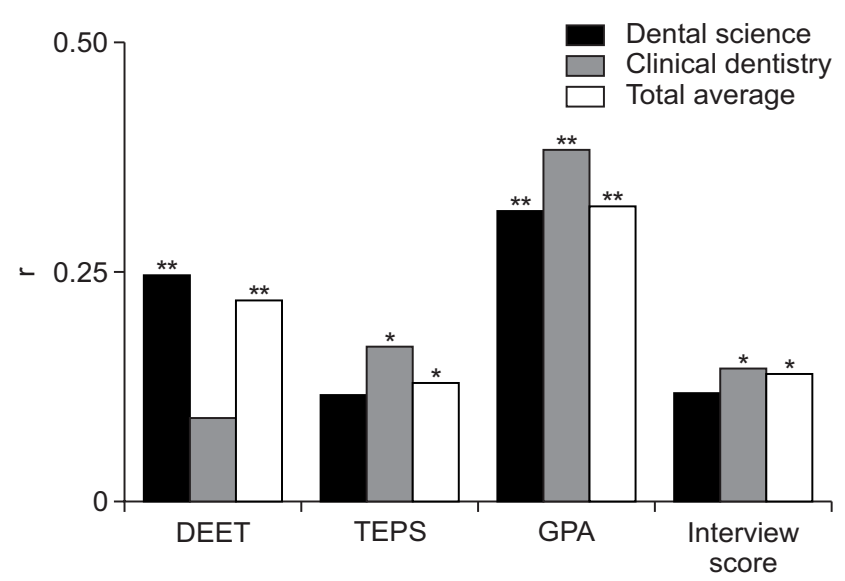

Fig. 6. Comparison of analysis results by correlation coefficient. DEET, Dental Education Eligibility Test; TEPS, Test of English Proficiency developed by Seoul National University; GPA, Grade Point Average. ${ }^{*} p<0.05,{ }^{* *} p<0.01$.

치의학 과목점수보다 임상치의학 과목점수에서 남녀차이가 두 드러진 본 연구의 결과와 유사한 것이라 할 수 있다. 각 학교별 로 수업방식이나 시험 성격이 차이가 있으므로 일반화시키기는 어려울 수 있으나, 전남대학교 치의학전문대학원 내에서는 여 학생들이 남학생들보다 우수한 성적을 거두었음이 통계적으로 유의하게 확인되었다.

성별에 따른 학업성취도 차이와 달리 연령에 따른 학업성취 도의 차이점은 발견하기 어려웠다. 이는 충북대학교 의학전문 대학원의 결과나 의과대학 성적과 연령 사이의 관계가 미비하 다는 Ramsbottom-Lucier 등[9]의 결과와 일치하는 것이다 [2]. 그러나 가천의과대학교나 Hesser와 Lewis [10]의 연구에서 는 연령이 낮을수록 학업성취도가 높게 나타났고, 연령이 높을 수록 성적이 높다는 James와 Chilvers [11]의 연구결과도 있다 [1]. 이처럼 매우 연령에 따른 학업성취도에 관해서는 서로 다른 결과들을 보고하고 있으므로 추가적으로 연구 대상의 확대 등 을 통한 보다 많은 연구들이 수행되어야 할 것으로 생각된다.

출신대학에 따라 학생들을 분류하여 학업성취도를 분석한 결 과, 서울 소재 대학을 졸업한 학생들이 지방 소재 대학 졸업 학 생들보다 우수한 성적을 보였으나, 우수한 대학으로 알려진 몇 몇 학교를 졸업한 학생들과 그렇지 않은 학생들로 구분하여 비 교하였을 때에는 통계적으로 유의한 차이를 발견할 수 없었다. 따라서 단순히 졸업한 학교의 이름만으로 그 학생의 치의학전 문대학원 성적을 유추하기는 어려울 것으로 생각되었다. 다른 연구에서는 학생들을 출신 학교가 아닌 학부전공별로 구분하여 학업성취도와 비교·분석하였는데 이런 접근 방법이 조금 더 의 미 있는 결과를 도출할 수 있을 것으로 생각되었다[12].

모집 구분에 따른 학업성취도에서 수시를 통해 입학한 학생 
들이 정시를 통해 입학한 학생들에 비해 학업성취도가 높았다. 이는 수시의 경우, GPA나 TEPS점수 등의 지원 자격 제한 요건 이 정시보다 높기 때문에 정시보다 상대적으로 우수한 학생들 이 지원하는 비율이 더 높은 것에 기인한 것으로 생각되었다.

입학전형요소 중 $\mathrm{GPA}$ 와 DEET점수가 학업성취도와 유의한 상관관계가 있었으나, TEPS점수와 면접점수는 통계적 유의성 이 매우 적거나 없었다. 이런 결과는 가천의과대학교나 충북대 학교 의학전문대학원의 연구결과와 매우 유사했다[1,2]. 가천 의과대학교의 연구에서 GPA와 의학 입문검사(Medical Education Eligibility Test, MEET) 성적은 학업성취도와 유의한 상관 관계를 보이지만, 공인영어성적과 심층면접점수는 학업성취도 와 상관성이 없다고 했고, 충북대학교 의학전문대학원은 공인 영어성적은 학업성취도와 무관하지만, GPA 성적은 학업성취도 와 큰 상관관계를 보였으며 MEET점수 역시 그 정도는 비교적 약하지만, 유의한 상관관계를 보인다고 했다[1,2].

학부 GPA 성적은 장기간의 학교생활 동안 축적되는 성적이 라는 점에서 치의학전문대학원 진학 이후의 학업성취도와 성격 이 매우 비슷하다. 반면 DEET점수는 몇 시간 동안 치러지는 일 회적인 시험성적이라는 점에서 그 성격이 다르다. 즉, GPA 성 적은 학교생활의 성실성을 보여주는 지표로써, 다른 요소들보 다 학업성취도를 예측하는 데 더 도움을 줄 수 있을 것이라 여겨 진다. 또한, 학년이 올라갈수록 GPA 성적과 학업성취도의 상관 관계가 커지는데, 다양한 임상실습과 많은 교과목을 소화해야 하는 임상치의학 과정에서는 기초치의학 과정보다 더 성실함이 요구되기 때문이라 생각해볼 수 있다. 반면 DEET의 세부과목 이 기초치의학 과목과 직접적으로 연결되기에, DEET점수는 임 상치의학보다는 기초치의학 성적과 연관성이 더 뚜렷한 것으로 해석된다. 해외의 GPA성적과 학업성취도 간에 상관관계가 존 재한다는 연구나, 미국 및 캐나다에서 의과대학 진학을 위해 치 루는 Medical College Admission Test가 학업성취도와 유의한 상관관계를 보인다는 결과의 연구들은 본 연구 결과를 뒷받침 하는 결과들이라 하겠다[13-15].

공인영어성적의 경우, 학업성취도와의 상관관계는 거의 없었 다. 그러나 영어가 다양한 학문연구의 기초로 매우 중요한 요소 일 뿐 아니라 국제화 시대에 걸맞은 의사소통 능력과 다양한 소 양을 가진 의료인들을 육성하고자 하는 전문대학원의 취지에도 부합하는 만큼 공인영어성적은 학생선발에 있어 꼭 필요한 요 소로 여겨진다[16,17]. 면접점수 또한 학업성취도와의 상관관 계는 거의 없지만, 학업성취도 외에 필요한 공감능력, 대화능력 등을 평가할 수 있기 때문에 면접 방식이나 내용들을 보다 잘 개 선하여 적용할 수 있는 방법을 찾아야 할 것이다[18].

본 연구는 입학연도별 입학전형요소가 조금씩 다르다거나, 유의한 상관관계를 보인 GPA나 DEET점수와 학업성취도 간의
상관계수가 다른 연구들에 비해 크지 않기 때문에 결과를 일반 화할 수 없다는 등의 한계점을 갖는다. 그럼에도 불구하고 본 연 구의 결과들은 미래의 우수 학생선발을 위한 참고자료로 사용 될 수 있을 것이다. 향후 학부전공과 같이 더 다양한 요소들과 학업성취도를 비교분석하고, 치의학전문대학원 성적뿐 아니라 졸업고사, 국가고시 등의 성적과 입학전형요소를 비교해 보는 등의 추가 연구가 수행된다면, 보다 훌륭한 예비의료인을 선발 하는 데 도움이 될 것으로 기대할 수 있다.

\section{CONFLICTS OF INTEREST}

The authors declare that they have no competing interests.

\section{ORCID}

\author{
Han-Joo Jung \\ https://orcid.org/0000-0002-2030-1068 \\ Eun-Ju Lee \\ https://orcid.org/0000-0001-5253-6630 \\ Min-Seok Kim \\ https://orcid.org/0000-0001-5910-8268
}

\section{REFERENCES}

1. Park KH, Hong DH, Oh JH, Park YB, Shin DJ, Lee YD. The analysis of academic achievements of students at gachon medical school. Korean J Med Educ 2006;18:289-296. doi: 10.3946/kjme.2006.18.3.289.

2. Lee SJ, Choi W, Kim SY, Choi JW. Correlation of academic achievements with cognitive admission variables and demographics at chungbuk national university graduate medical school. Korean J Med Educ 2009;21:59-66. doi: 10.3946/kjme.2009.21.1.59.

3. Kang HC, Kim NH, Shin SH, Lee KH, Lee SM, Lee YS, Chang JH, Han ST, Hwang SH. Data analysis for oral health professional. Seoul: Hannarae Publishing co.; 2011. p. 191198.

4. Kang HC, Kim NH, Shin SH, Lee KH, Lee SM, Lee YS, Chang JH, Han ST, Hwang SH. Data analysis for oral health professional. Seoul: Hannarae Publishing co.; 2011. p. 269276.

5. Ahn D, Im H, Kim KS. Correlation study of the scores of entrance examination, graduation examination and national licensure examination at Korea university medical college. Korean J Med Educ 2000;12:91-96. doi: 10.3946/ kjme.2000.12.1.91. 
6. Ahn SS, Seo YK, Baek SE, Bae SY, Seol JH, Lee HY, Park EC. The correlation of grade point average of medical school and the score of Korean medical licensing examination. Korean J Med Educ 2004;16:25-32. doi: 10.3946/ kjme.2004.16.1.25.

7. Kim HW, Ko HS, Lee MS, Nam JH, Kim WD, Lee JD. The influence of admission characteristics on premedical school achievement at a medical school. Korean J Med Educ 2002;14:257-268. doi: 10.3946/kjme.2002.14.2.257.

8. Peng R, Khaw HH, Edariah AB. Personality and performance of preclinical medical students. Med Educ 1995;29:283-288. doi: 10.1111/j.1365-2923.1995. tb02850.x.

9. Ramsbottom-Lucier M, Johnson MM, Elam CL. Age and gender differences in students' preadmission qualifications and medical school performances. Acad Med. 1995; 70:236-239.

10. Hesser A, Lewis L. Prematriculation program grades as predictors of black and other nontraditional students' firstyear academic performances. Acad Med 1992;67:605-607. doi: 10.1097/00001888-199209000-00015.

11. James D, Chilvers C. Academic and non-academic predictors of success on the Nottingham undergraduate medical course 1970-1995. Med Educ 2001;35:1056-1064. doi: 10.1046/j.1365-2923.2001.01042.x.

12. Yoo HH. Analysis on a medical school students' academic achievement by university major field. J Korean Cont As- soci 2014;14:634-638. doi: 10.5392/JKCA.2014.14.09.634.

13. Hall FR, Bailey BA. Correlating students' undergraduate science GPAs, their MCAT scores, and the academic caliber of their undergraduate colleges with their firstyear academic performances across five classes at Dartmouth Medical School. Acad Med 1992;67:121-123. doi: 10.1097/00001888-199202000-00017.

14. Colliver JA, Verhulst SJ, Williams RG. Using a standardizedpatient examination to establish the predictive validity of the MCAT and undergraduate GPA as admissions criteria. Acad Med 1989;64:482-484. doi: 10.1097/00001888198908000-00014.

15. Jones RF, Thomae Forgues M. Validity of the MCAT in predicting performance in the first two years of medical school. J Med Educ 1984;59:455-464. doi: 10.1097/00001888-198406000-00001.

16. Choi JJ. Education for doctors needed in new era. Education Policy Forum 2005;108:14-17.

17. Yang EB. An inquiry into the professional graduate medical school. Korean J Med Educ 2001;13:317-332. doi: 10.3946/kjme.2001.13.2.317.

18. Rahbar MH, Vellani C, Sajan F, Zaidi AA, Akbarali L. Predictability of medical students' performance at the Aga Khan University from admission test scores, interview ratings and systems of education. Med Educ 2001;35:374380. doi: 10.1046/j.1365-2923.2001.00760.x. 